\title{
Diálogo urología anatomía patológica ¿qué información espera el urólogo del patólogo?
}

\author{
Castiñeiras Fernández J*, Ruiz Cerdá JL** \\ *Presidente de la Asociación Española de Urología. **Director de Actas Urológicas Españolas.
}

Actas Urol Esp. 2007;31(9):943

$\mathrm{L}^{2}$ a comunicación entre profesionales médicos es esencial para el intercambio de conocimientos. La relación entre urólogos y anatomopatólogos es especialmente importante. De ella se derivan decisiones terapéuticas que condicionan la evolución del paciente. No es necesario poner ejemplos. Todos tenemos en mente pacientes oncológicos sobre-tratados e infra-tratados.

Entenderse es complejo y difícil. Para que la comunicación sea efectiva es necesario disponer de un lenguaje común. Además, el significado de las palabras tiene que ser el mismo para todos aquellos que las usan. Pero el punto más importante en este diálogo es ponerse en el lugar del interlocutor. El urólogo debe conocer las dificultades a las que se enfrenta el anatomopatólogo a la hora de emitir su informe. El anatomopatólogo por su parte, debe conocer las consecuencias que se derivan del mismo y la responsabilidad a la que se enfrenta el urólogo cuando toma decisiones individuales. Lamentablemente, este aspecto de la comunicación entre urólogos y anatomopatólogos no siempre es el adecuado. Si bien, la responsabilidad de la distancia existente entre ambas especialidades recae más en las condiciones de trabajo que en la falta de voluntad de los profesionales.

La uropatología ha experimentado un gran avance en las últimas décadas, sobre todo como consecuencia del aumento de la realización de biopsias. Muchos de esos avances de nuestro conocimiento uropatológico están reflejados en las páginas de este número monográfico de Actas Urológicas Españolas. Este es un monográfico escrito por anatomopatólogos específicamente para urólogos. Su objetivo ha sido llamar la atención sobre los temas más comunes, prácticos y controvertidos, mayoritariamente sobre uropatología oncológica, a los que se enfrenta el urólogo en la actualidad. Los autores han realizado un esfuerzo evidente de síntesis, actualización y revisión de la literatura de cada uno de los temas. Pero sobre todo, hay que agradecerles el hecho de que, al escribir, lo han llevado a cabo siempre poniéndose en el lugar de los urólogos.

La información contenida en cada uno de sus artículos nos va a permitir entender mejor los informes anatomopatológicos y su significado para el paciente.

La Asociación Española de Urología quiere agradecer la labor completamente desinteresada de todos los autores participantes en este monográfico y, sobre todo, de su editora la doctora Pilar González. Actas Urológicas Españolas no ha querido escatimar recursos en la edición de este monográfico. Prueba de ello son la gran cantidad de fotos a color y esquemas que contiene. Todo con un fin último: que permita mejorar el diálogo entre urólogos y anatomopatólogos. 